\title{
Anomalous left coronary artery from the pulmonary artery: a 15 year sample*
}

\author{
SAMUEL MENAHEM, ALEXANDER W VENABLES \\ From the Department of Cardiology, Royal Children's Hospital, Melbourne, Australia
}

SUMMARY Eleven patient with anomalous left coronary artery arising from the pulmonary artery were identified from the beginning of 1970 to the end of 1985 . The only male patient presented at the age of eight years for assessment of a murmur and was symptom free. The remainder presented in infancy with features of cardiac failure. The electrocardiogram was abnormal in all patients, the majority showing anterolateral ischaemia. Cross sectional echocardiography when available showed a dilated, poorly contracting left ventricle, and in two cases what appeared to be a "normal" origin of the left coronary artery. Aortography was performed in 10 patients and led to the correct diagnosis in eight. The diagnosis was made at necropsy in three infants. One patient has remained well without treatment. The anomalous left coronary artery was ligated in three of the earlier patients, including the asymptomatic boy. Two of these cases had concurrent saphenous vein graft to the anomalous left coronary artery. The four most recent cases were treated by successful direct reimplantation of the anomalous left coronary artery to the aorta when they first presented in infancy. They continue to improve symptomatically and show objective improvement of myocardial function.

In this recent experience supports our policy of early surgical re-establishment of a two coronary system from the aorta.

Anomalous left coronary artery arising from the pulmonary artery is a rare congenital abnormality occurring in approximately 1 in 300000 live births. ${ }^{1}$ It is important to recognise this rare disorder because newer surgical techniques, which permit direct anastomosis of the anomalous left coronary artery to the aorta, have considerably improved both morbidity and mortality. ${ }^{2}$ Without treatment the majority of patients develop congestive heart failure once the pulmonary vascular resistance begins to fall and run-off occurs from the right coronary artery to the left coronary artery and then into the pulmonary artery. A coronary "steal" develops, leading to ischaemia and possible infarction and fibrosis of the

^ Presented to the Cardiac Society of Australia and New Zealand in April 1986.

Requests for reprints to Dr Samuel Menahem, Department of Cardiology, Royal Children's Hospital, Parkville, Victoria 3052, Australia.

Accepted for publication 5 May 1987 anterolateral wall of the left ventricle. Such patients die in infancy. ${ }^{3}$ An occasional patient whose collateral circulation is developed and effectively distributed may remain symptom free and present late in childhood or adult life. ${ }^{45}$

In this report we describe our experience of this rare congenital abnormality and highlight the diagnostic features and changes in management, particularly the move towards early surgical reestablishment of a two coronary artery system.

\section{Patients and methods}

A retrospective study was undertaken of all patients in whom anomalous left coronary artery was diagnosed at the Royal Children's Hospital, Melbourne from 1970 to 1985 . We reviewed the details of the clinical data, investigations, treatment, and necropsy findings, where available, and noted the outcome of the survivors. 


\section{Results}

Eleven patients were diagnosed as having anomalous left coronary artery from 1970 to 1985 . Ten were females, nine of whom presented between the ages of 2-5 months with a history of poor feeding, recent weight loss, breathlessness, and often respiratory infection. All had signs of cardiac failure. Development of an apical systolic murmur suggestive of mitral incompetence was common. One child presented at the age of four years for evaluation of mitral incompetence after attending another hospital at three months with an acute illness diagnosed as "bronchiolitis". The only boy in the series was seen at the age of eight years for assessment of a murmur.

All except the symptom free boy had $x$ ray evidence of cardiomegaly, often with features of pulmonary congestion and pulmonary collapse or consolidation. In 10 patients the electrocardiogram showed anterolateral ischaemia or actual infarction (fig 1). One patient had evidence of left ventricular hypertrophy. Two patients showed evidence of left atrial hypertrophy and one patient had low voltage complexes.

Cross sectional echocardiography was performed on the last five patients. All had evidence of a poorly contracting dilated left ventricle (fig 2 ). The anoma- lous left coronary artery was definitely seen to arise from the main pulmonary artery in only one patient (fig 3). In two others the diagnosis was suspected, while in a further two cases an apparently "normal" left coronary artery was seen to arise from the aortic sinus (fig 4).

Enzyme studies were done on one patient only. Activities were increased at and soon after presentation. A thallium radioisotope scan carried out in one patient showed a somewhat dyskinetic anterolateral segment of the left ventricle.

No further study was undertaken in one patient in whom the echocardiogram was thought to be normal. Cardiac catheterisation was carried out in the remaining 10 patients. In the one patient where the echocardiogram was thought to be diagnostic, aortography confirmed the diagnosis of an anomalous left coronary artery arising from the main pulmonary artery. This vessel filled retrogradely from the dilated right coronary artery and was seen to drain into the main pulmonary artery (fig $5 \mathrm{a}$ and $\mathrm{b}$ ).

In the other nine patients left ventricular angiography showed a dilated, poorly contracting left ventricle with varying degrees of mitral incompetence. One patient also had a small ventricular septal defect and a ductus arteriosus. In this patient a poor quality aortogram did not define the anomalous left coronary

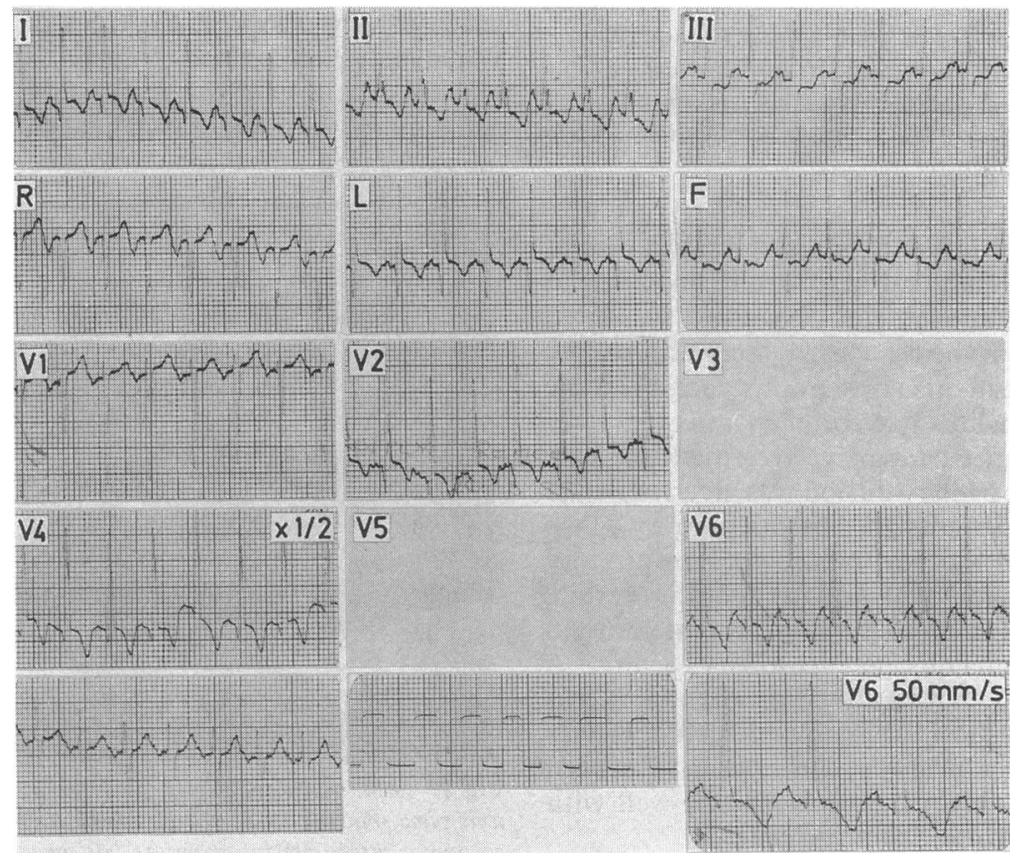

Fig 1 Electrocardiogram of infant at 10 weeks with anomalous left coronary artery. It shows a $Q$ wave and $T$ wave inversion in $I, a V L$, and lateral chest leads. There is ST elevation in V2. 


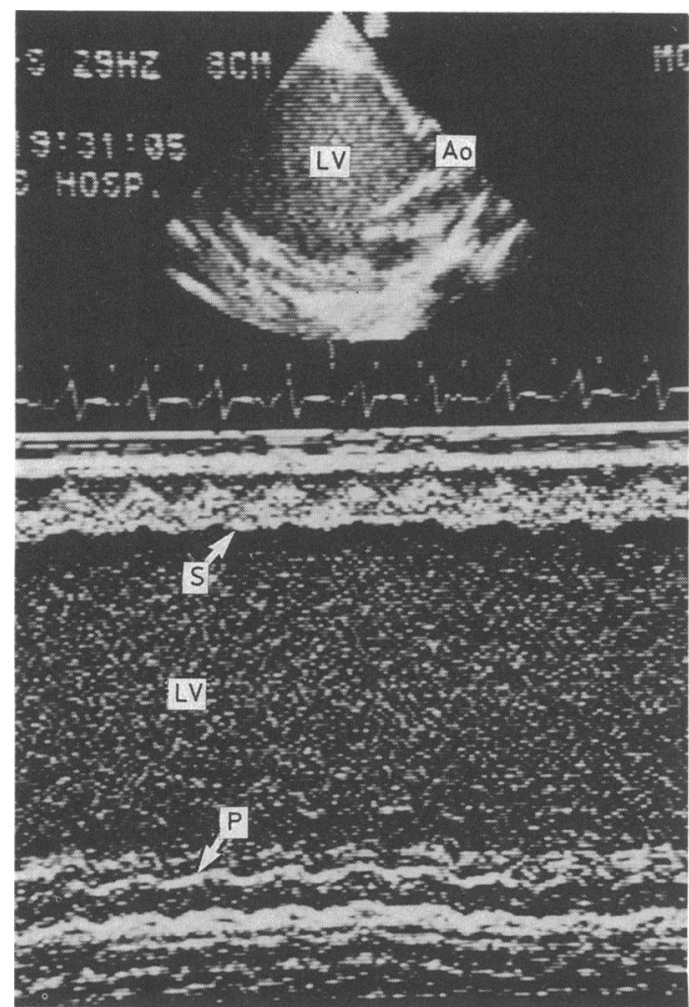

Fig 2 Cross sectional and $M$ mode echocardiogram of infant at 4 months with anomalous left coronary artery showing grossly dilated, poorly contracting left ventricle. Ao, aorta; $L V$, left ventricle; $S$, ventricular septum; $P$, left ventricular posterior wall.

artery. In a further infant the aortogram was also of poor quality. The right coronary artery appeared to arise normally and the left coronary artery was filled without its ostium being clearly defined. In the remaining seven patients aortography confirmed the diagnosis of anomalous left coronary artery.

All infants required intensive treatment for cardiac failure. A dopamine infusion was given to two of the more recent patients just before surgery. Two infants died from cardiac failure and respiratory infection at the ages of 9 and 10 months despite intensive medical treatment without antemortem diagnosis of anomalous left coronary artery. A further infant died shortly after ligation of a ductus arteriosus, the diagnosis of anomalous left coronary artery being made at necropsy. One patient has been treated conservatively. She has remained well with stable, moderate mitral incompetence.

All the other patients were treated by operation. One had ligation of the anomalous left coronary artery at the age of 15 months. She developed effort

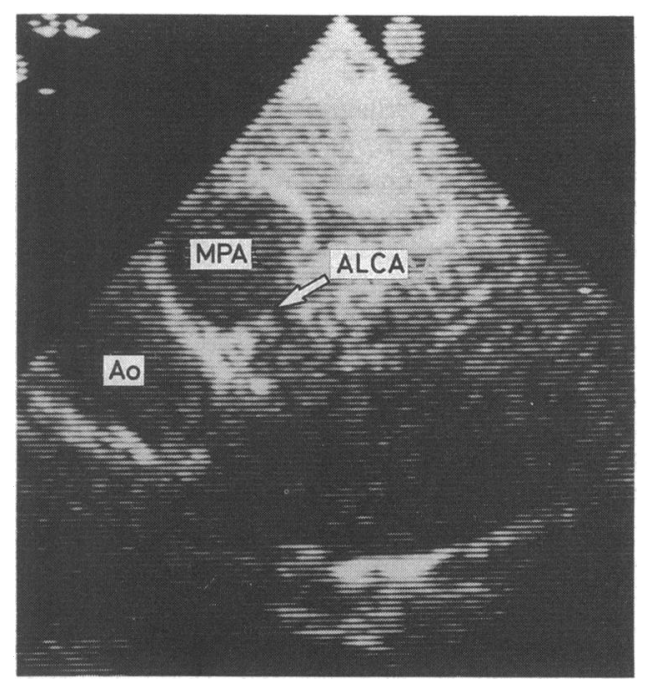

Fig 3 Cross sectional echocardiogram in high parasternal short axis view showing the anomalous left coronary artery ( $A L C A)$ arising from the main pulmonary artery trunk. Ao, aorta, $M P A$, main pulmonary artery.

angina at the age of 12 years and has since had a saphenous vein graft to the left coronary artery. Two other children had ligation of the anomalous left coronary artery as it entered the main pulmonary artery and a concurrent saphenous vein graft to the left coronary artery at the ages of 5 and 8 years. When restudied one and five years later, aortography showed occlusion of the grafts (fig 6 ). One has since had a mitral valve replacement at the age of 18 years for worsening mitral incompetence.

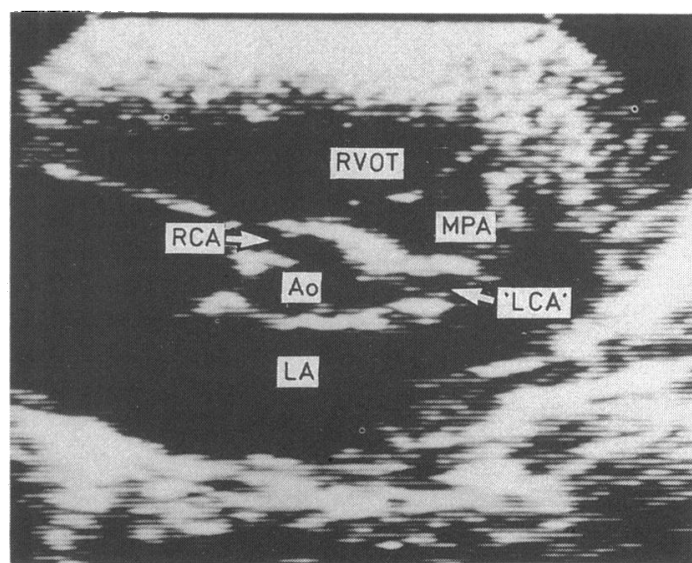

Fig 4 Cross sectional echocardiogram in parasternal short axis view showing what appears to be a normal left coronary artery arising from the left aortic sinus. Ao, aorta; $L A$, left atrium; ' $L C A$ ', 'left coronary artery'; $M P A$, main pulmonary artery; $R C A$, right coronary artery; RVOT, right ventricular outflow tract. 


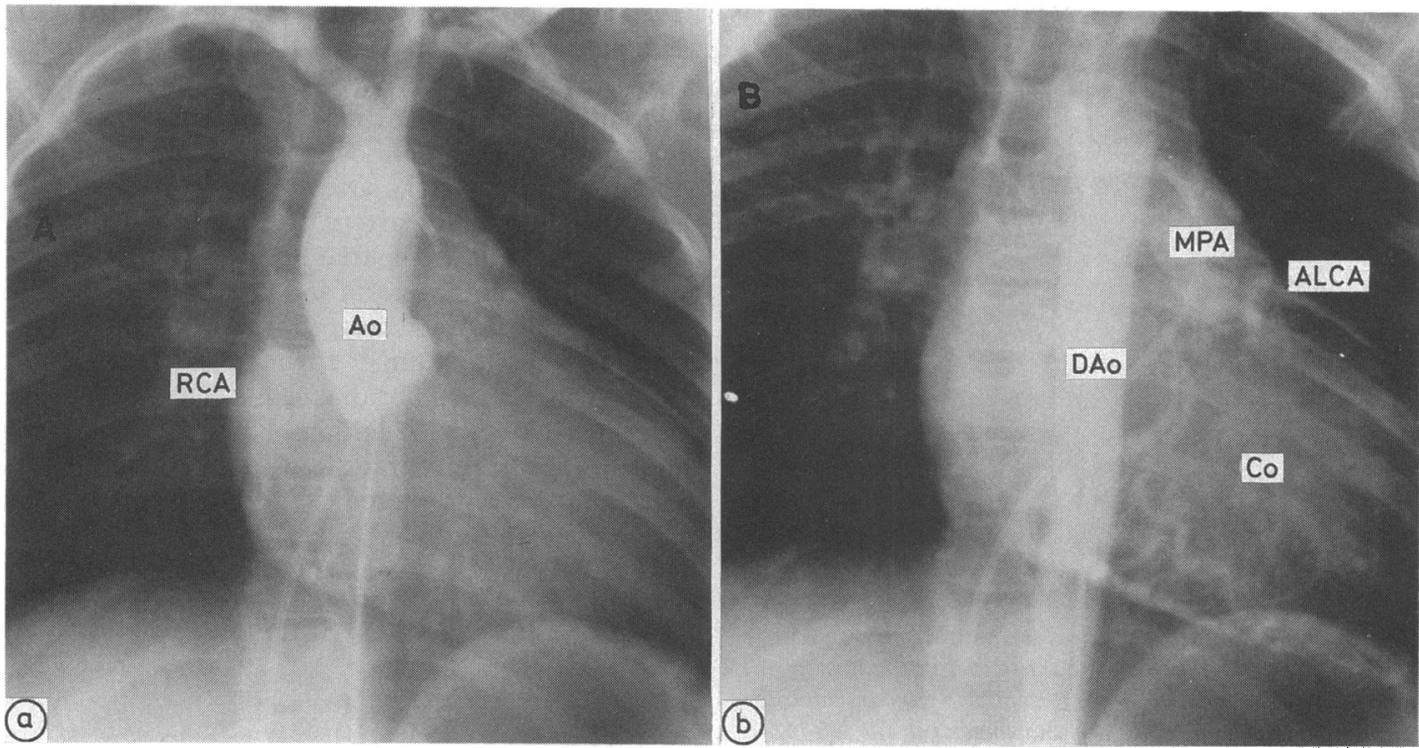

Fig 5 Aortograms in a patient with an anomalous left coronary artery. (a) Aortic root injection showing filling of a dilated right coronary artery with no filling of the left coronary artery. (b) A later frame showing filling of the left coronary artery via a number of collaterals with subsequent opacification of the main pulmonary artery. Ao, aorta; MPA, main pulmonary artery; $R C A$, right coronary artery; Co, collaterals.

In the four most recent patients seen between 1979 and 1985 a direct anastomosis of the anomalous left coronary artery to the aorta was carried out once the diagnosis of anomalous left coronary artery was made. The technique used was that described by Takeuchi et $a l,{ }^{2}$ in which a flap of pulmonary arterial wall is raised to form a coronary tunnel inside the pulmonary artery between a created aortopulmonary window and the left coronary artery ostium. When these patients were restudied six months and one and three years later there was improved contraction of the left ventricle but residual mitral incompetence. The newly anastomosed left coronary artery was patent (fig 7). One patient has developed mild main pulmonary artery stenosis. All four patients have shown considerable improvement in their symptoms, $x$ ray, and electrocardiogram and a return towards normal left ventricular function on echocardiography and radionuclide studies. Follow up has lasted from six months to six years. Figure 8 summarises the findings.

\section{Discussion}

This review of an Australian sample correlates well with experience in North America and South Africa. ${ }^{5-7}$ There was a preponderance of girls and most presented in early infancy with features of cardiac failure. If the anomalous left coronary artery was not recognised early death ensued, with evidence of fibrosis or infarction of the left ventricle at necropsy. However, two patients presented late and one has remained well without operation, as was seen in

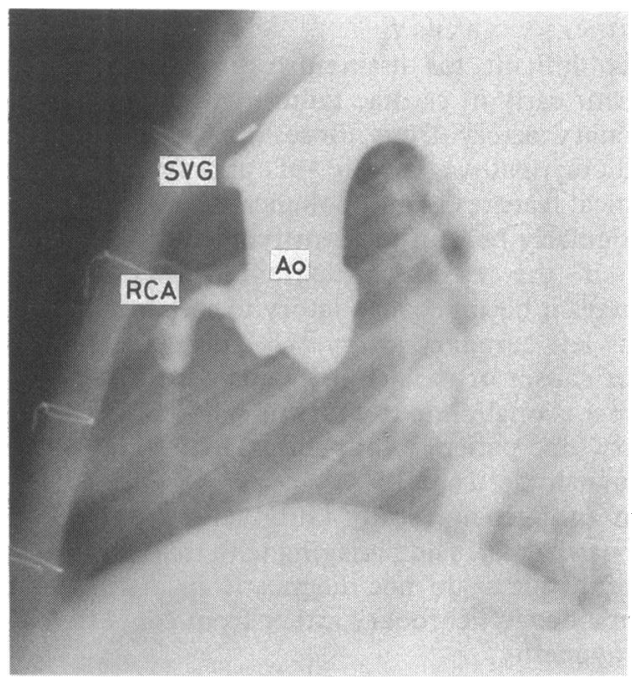

Fig 6 Aortogram after aortic root injection showing a dilated right coronary artery filling from the right coronary sinus. The occluded stump of the saphenous vein graft is shown. Ao, aorta; $R C A$, right coronary artery; SVG, saphenous vein graft stump. 


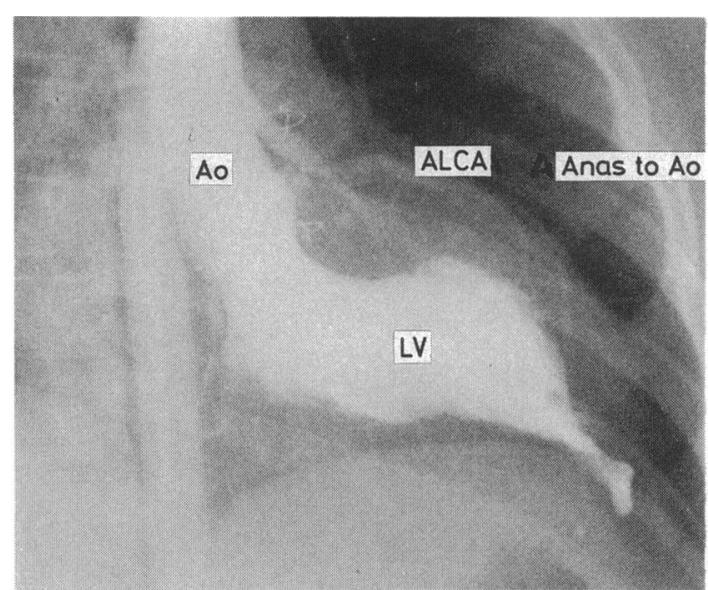

Fig 7 Left ventricular angiogram three years after a Takeuchi reimplantation of the anomalous left coronary artery to the ascending aorta via a tunnel in the floor of the main pulmonary artery. The left ventricle was contracting well. The angiogram shows the anastomosis to the left coronary artery. Ao, aorta, Anas, anastomosis; LV, left ventricle.

earlier reports. ${ }^{4-8}$ Presumably an effective and well distributed collateral circulation allowed this patient to survive. Long term follow up of such patients suggested that arrhythmias may cause sudden death. ${ }^{4}$

\section{THE DIAGNOSIS OF ANOMALOUS LEFT} CORONARY ARTERY

It is difficult to distinguish those patients who present early in cardiac failure with anomalous left coronary artery from those who have congestive cardiomyopathy, usually of uncertain aetiology. Clinical features and radiological assessment are not particularly helpful in identifying the two groups, ${ }^{6}$ but if the electrocardiogram shows ischaemic changes it becomes mandatory to seek out an anomalous left coronary artery..$^{5-6}$ There are, however, other causes of ischaemic changes in infancy, ${ }^{5}$ and the occasional patient with anomalous left coronary artery (one patient in our series) may show left ventricular hypertrophy. ${ }^{6}$

In an extensive study Gutgesell et al found that myocardial perfusion imaging with thallium-201 was helpful, but again not diagnostic in distinguishing anomalous left coronary artery from congestive cardiomyopathy. ${ }^{9}$

Several recent studies have extolled the virtues of cross sectional echocardiography. ${ }^{10-13}$ All have documented the dilated, poorly contracting left ventricle, doing away with the need for left ventricular angiography. Although some patients were shown to have anomalous left coronary artery arising from the main pulmonary artery trunk, Robinson et al emphasised the potential for false negative diagnosis, ${ }^{13}$ as we found in two of our cases. The anomalous left coronary artery is in almost an identical position as a normal left coronary artery except that it arises from the pulmonary artery trunk. Robinson et al suggested that the echo-free linear structure apparently arising from the aorta and resembling a normal left coronary artery was probably the transverse sinus of the pericardium. ${ }^{13}$ Imaging of a dilated right coronary artery was not diagnostic. Our experience with pulsed Doppler is limited. King et al suggested that late systolic retrograde flow in the proximal pulmonary artery represented retrograde flow from the anomalous left coronary artery. ${ }^{12}$

Aortography remains essential for definitive diagnosis, but despite such investigation the abnormality
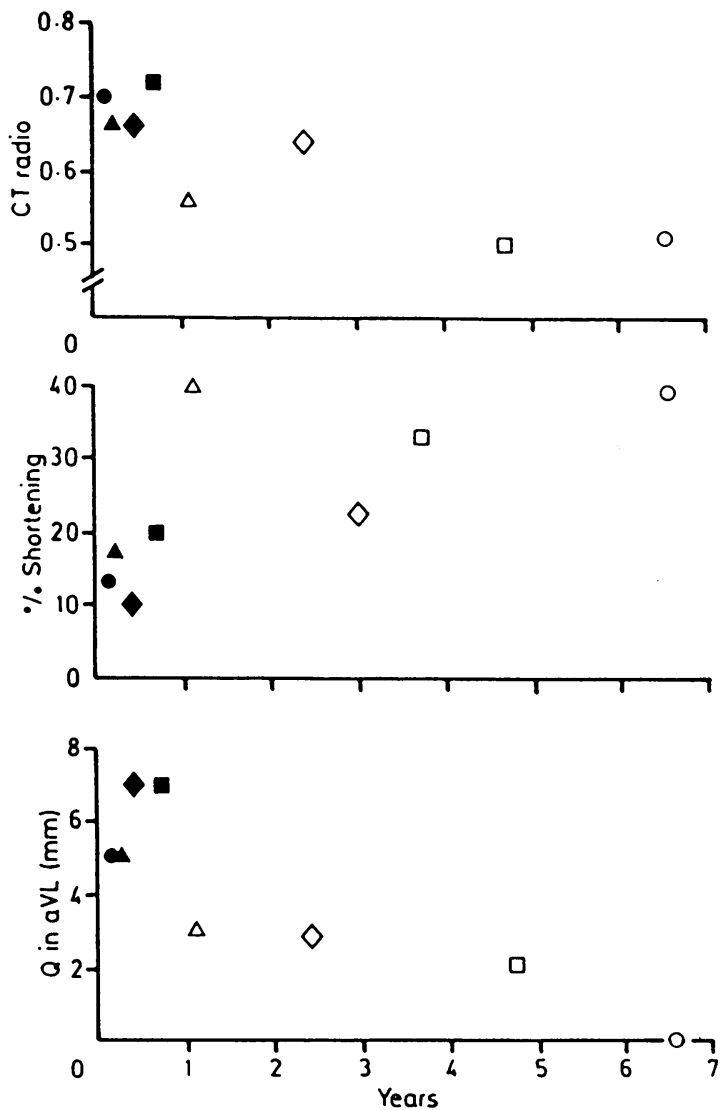

Fig 8 Changes in left ventricular function after re-establishment of two coronary artery systems from the aorta by the Takeuchi approach. CT ratio, cardiothoracic ratio, $\%$ shortening, left ventricular shortening fraction; $Q$ in aVL, depth of $Q$ wave in lead aVL. $\diamond$, patient who moved to another state. Black symbols show values before operation. Open symbols are values after operation. 
was missed in two of our cases. In retrospect this result arose from poor quality angiography with lack of clear delineation of the origin of both coronary arteries. Selective right coronary angiography has been especially helpful in demonstrating the dilated right coronary artery and late filling of the anomalous left coronary artery with a subsequent blush of opacification in the main pulmonary artery. Our one case in an infant with a ventricular septal defect and ductus arteriosus illustrates the need to look at the coronary arteries carefully even when another congenital heart abnormality is found, especially if the infant does poorly after operation. ${ }^{5}$

\section{TREATMENT OF ANOMALOUS LEFT CORONARY ARTERY}

Most of our patients required intensive and prolonged medical treatment of heart failure both before and after operation. In the two more recent patients a dopamine infusion was found especially helpful in preparing the patient for early operation. One patient remained stable without treatment; this case illustrates the variability of the condition. ${ }^{4}$

Househam et al reviewed the surgical options available. ${ }^{7}$ They argue for a conservative approach particularly in the older infant because only one of their three infants who had reimplantation of the anomalous left coronary artery into the aorta survived. In 1981 Driscoll et al also argued for a conservative approach because only two of their eight patients operated on before the age of twelve months survived. ${ }^{8}$ They advocated operation during childhood because 13 out of their 15 patients survived when operated on between 14 months and 12 years. Ligation of the anomalous left coronary artery may lead to subsequent angina, as shown by one patient in our series and others reported elsewhere, ${ }^{14}$ or increased mortality. ${ }^{815}$ If a two coronary artery system can be safely re-established from the aorta it is preferable to conservative treatment or ligation of the anomalous left coronary artery, as Arciniegas et al have emphasised. ${ }^{15}$ Six of their infants and three of ours died after medical treatment. Successful reestablishment of a two coronary artery system restores the blood flow to the left ventricular myocardium immediately and more completely. ${ }^{15}$ This result may considerably reduce mortality and morbidity and permit more complete recovery of the myocardium. The last four patients in our series, who have had an anastomosis of the anomalous left coronary artery to the aorta by the Takeuchi et al approach, ${ }^{2}$ have all survived. They had an excellent result with proven patency of the anastomosed vessel on catheter restudy. Their symptoms have improved considerably and $x$ ray and electrographic findings on follow up (12 months-7 years) are becoming more normal.

Anastomosis of the anomalous left coronary artery to the aorta is a major advance. It is important to seek out this rare condition to enable corrective surgery to be performed and thereby improve the mortality and long term morbidity. We do not believe that it is possible, as Driscoll et al suggest, ${ }^{8}$ to identify those infants who present in cardiac failure and may survive into childhood with medical treatment from those who will succumb. An active policy seems justified.

\section{Conclusions}

Anomalous left coronary artery should be considered in any infant with congestive cardiomyopathy or apparent congenital mitral incompetence. The possibility of this anomaly is increased if ischaemic changes are noted on the electrocardiogram. Cross sectional echocardiography will certainly demonstrate a poorly contracting, dilated left ventricle. Although in some cases it is possible to show the anomalous left coronary artery arising from the main pulmonary artery just distal to the pulmonary valve, cross sectional echocardiography may also show what appears to be a "normal" origin of the left coronary artery. Good quality angiography remains essential in making a definitive diagnosis. Direct reimplantation of the anomalous left coronary artery into the aorta is likely to become the treatment of choice because it improves mortality and long term morbidity.

\section{References}

1 Keith JD. The anomalous origin of the left coronary artery from the pulmonary artery. $\mathrm{Br}$ Heart $J$ 1959;21:149-61.

2 Takeuchi S, Imamura H, Katsumoto K, et al. New surgical method for repair of anomalous left coronary artery from pulmonary artery. $J$ Thorac Cardiovasc Surg 1979;78:7-11.

3 Wesselhoeft H, Fawcett JS, Johnson AL. Anomalous origin of the left coronary artery from the pulmonary trunk. Circulation 1968;38:403-25.

4 Moodie DS, Fyfe D, Gill CC, et al. Anomalous origin of the left coronary artery from the pulmonary artery (Bland-White-Garland syndrome) in adult patients: long term follow-up after surgery. Am Heart $J$ 1983;106:381-8.

5 Lurie PR. Abnormalities of the coronary vessels. In: Moss AJ, Adams FH, Emmanouilides GC, eds. Heart disease in infants, children and adolescence. 2nd ed. Baltimore: Williams and Wilkins, 1977:484-9.

6 Keith JD. Diseases of the coronary arteries and aorta. In: Keith JD, Rowe RD, Vlad P, eds. Heart disease in 
infancy and childhood. New York: Macmillan, 1978:1914-9.

7 Househam KC, Human DG, Fraser CB, Joffe HS. Anomalous left coronary artery from the pulmonary artery-a therapeutic dilemma. S Afr Med J 1983;63:325-7.

8 Driscoll DJ, Nihill MR, Mullins CE, Cooley DA, McNamara DG. Management of symptomatic infants with anomalous origin of the left coronary artery from the pulmonary artery. Am J Cardiol $1981 ; 47: 642-8$.

9 Gutgesell HP, Pinsky WW, De Puey EG. Thallium201 myocardial perfusion imaging in infants and children. Value in distinguishing anomalous left coronary from congestive cardiomyopathy. Circulation 1980;61:596-9.

10 Caldwell RL, Hurwitz RA, Girod DA, Weyman AE, Feigenbaum $H$. Two-dimensional echocardiographic differentiation of anomalous left coronary artery from congestive cardiomyopathy. Am Heart J 1983;106:710-6.
11 Terai M, Nagai Y, Toba T. Cross-sectional echocardiographic findings of anomalous origin of left coronary artery from pulmonary artery. $\mathrm{Br}$ Heart $\mathrm{J}$ 1983;50:104-5.

12 King DH, Danford DA, Hutha JC, Gutgesell HP. Non invasive detection of anomalous origin of left main coronary artery from the pulmonary trunk by pulsed Doppler echocardiography. Am J Cardiol 1985;55: 608-9.

13 Robinson PJ, Sullivan ID, Kumpeng V, Anderson RH, Macartney FJ. Anomalous origin of the left coronary artery from the pulmonary trunk. Potential for false negative diagnosis with cross sectional echocardiography. Br Heart J 1984;52:272-7.

14 McNamara DG, El-Said G. Treatment of anomalous origin of left coronary artery from the pulmonary artery. Eur J Cardiol 1973;1:497-9.

15 Arciniegas E, Farooki ZQ, Hakimi M, Green EW. Management of anomalous left coronary artery from the pulmonary artery. Circulation 1980;62 (suppl 1): 180-9. 